\title{
Evaluation of Some Modalities of Therapy in Idiopathic Trigeminal Neuralgia
}

\author{
Yosria A. Altaweel ${ }^{1}$, Mahmoud E.Elebeary ${ }^{1}$, Wafaa S. Mohamed ${ }^{1, *}$, Mohamed A. Alsadek ${ }^{2}$ \\ ${ }^{1}$ Departement of Neurology, Faculty of Medicine, Zagazig University, Egypt \\ ${ }^{2}$ Departement of Neurology, Naser Institute Hospital, Egypt \\ *Corresponding author: dr.wafaa74@yahoo.com
}

\begin{abstract}
The first-line management for idiopathic trigeminal neuralgia (ITN) is medical therapy. The effectiveness of medications typically wanes over time,so we need to evaluate other modality of therapy. Objective: To compare pharmacotherapy versus Gamma knife radiotherapy (GKRS) in relief of pain in patients with idiopathic trigeminal neuralgia (ITN). Methods: the study included sixty eight patients with idiopathic trigeminal neuralgia. They were assessed by Barrow Neurological Institute (BNI) pain intensity scale. They were classified into two groups: Group I: 34 patients, were treated by GKRS and were chosen from Gamma knife center in Nasser institute hospital. They were $19(55.9 \%$ ) male and 15 (44.1\%) female with ages ranged from 40-59 years (Mean \pm SD was 49.5 \pm 6.1 ). They were assessed by BNI scale before and immediately after GKRS, One month and three months after GKRS treatment. Group II: 34 patients, were chosen from neurology department Zagazig University Hospitals. They were 19 (55.9\%) male and 15 (44.1\%) female with ages ranged from 40-60 years (Mean $\pm \mathrm{SD}$ was 49.0 \pm 6.95$)$. They were assessed by BNI scale before and one week after pharmacotherapy, One month and three months after pharmacotherapy. Results: There was no statistically significant difference between the two groups regarding pain intensity before GKRS or pharmacotherapy $(p=0.33)$ while one week after pharmacotherapy ten $(29.4 \%)$ patients showed statistically significant improvement of pain.After one month, group I showed statistical significant better outcome $(41.2 \%)$ than group II $(8.8 \%)$. BNI score three months after managements was highly statisticallly significant better $(32.4 \%)$ among group I than group II $(\mathrm{p}=0.001)$. Most of group I $(82.4 \%)$ had good overall outcome while $50 \%$ of group II had fair outcome and $26.5 \%$ had good outcome.Conclusion: medical management of ITN had an initial good results in improving pain intensity which begins to wane over one month and the effect of GKRS begins to appear. The effect of GKRS on ITN pain is still evolving through three months follow up.
\end{abstract}

Keywords: idiopathic trigeminal neuralgia, pharmacotherapy, Gamma knife radiotherapy

Cite This Article: Yosria A. Altaweel, Mahmoud E.Elebeary, Wafaa S. Mohamed, and Mohamed A. Alsadek, "Evaluation of Some Modalities of Therapy in Idiopathic Trigeminal Neuralgia." International Journal of Clinical and Experimental Neurology, vol. 5, no. 1 (2017): 28-32. doi: 10.12691/ijcen-5-1-6.

\section{Introduction}

Trigeminal neuralgia (TN) is pain in one or more of the trigeminal nerve distribution in one side of the face. The pain is characterized by paroxysmal attacks in electric trigger areas that when stimulated brings on this classic type of pain. The condition is associated with periods of remission and exacerbation [1]. Most trigeminal neuralgia is idiopathic, but a small percentage is due to secondary causes as brain tumors or multiple sclerosis [2]. The firstline management for idiopathic trigeminal neuralgia (ITN) is medical therapy. Typical initial oral agents include carbamazepine, oxcarbazepine, gabapentin, phenytoin and baclofen, used alone or in combination. The effectiveness of medications typically wanes over time despite increasing doses, with many patients not able to tolerate side effects [3]. Gamma knife radiosurgery (GKRS) was first used by Leksell (1971) to treat ITN. GKRS is based on closed-cranial irradiation of intracranial targets using multiple photon beams after localization of the target(s) in stereotactic space. [4]. Unlike the surgical alternatives GKRS can be offered to every patient and is performed on an outpatient basis in addition to the relatively low incidence of procedure related complications [5].

\section{Subjects and Methods}

This study was conducted on 68 patients with idiopathic trigeminal neuralgia which were classified into two groups: Group I: 34 patients, were chosen from Gamma knife center in Nasser institute hospital. They were 19(55.9\%) male and $15(44.1 \%)$ female with ages ranged from 40-59 years ( Mean \pm SD was $49.5 \pm 6.1$ ). Group II: 34 patients, were chosen from neurology department Zagazig University Hospitals. They were 19 (55.9\%) male and 15 $(44.1 \%)$ female with ages ranged from 40-60 years (Mean \pm SD was $49.0 \pm 6.95$ ). The study was done during the period from January 2015 to December 2016. Informed consent was obtained from every participant.

Patients were selected according to the following criteria: 


\section{Inclusion criteria:}

1. Idiopathic trigeminal neuralgia confirmed clinically [6] and by brain magnetic resonance imaging (MRI).

2. Both sexes with ages ranged between $40-60$ years.

\section{Exclusion criteria:}

1. Secondary causes of trigeminal neuralgia as compression of the trigeminal nerve e.g tumors or other structural abnormalities such as arteriovenous malformations, or multiple sclerosis (MS).

2. Patients with system failure as renal, respiratory, liver failure or with malignancy.

3. Diabetic patients.

4. Patients with pacemakers, defibrillators or other implanted electronic devices cannot be scanned using magnetic resonance imaging (MRI)

5. pregnant patient or suspected that she may be pregnant as GKRS radiation exposure during pregnancy may lead to birth defects.

All patients were subjected to the following:

1- Complete history taking and thorough complete general and neurological examination.

2- Laboratory investigations to exclude secondary causes of TN

3- MRI brain was performed using a (GE 1.5 Tesla magnet) MRI machine. For all patients axial T2 FLAIR, axial or coronal $\mathrm{T} 2 \mathrm{~W}$, axial or sagittal T1W. Slice thickness was $1.6 \mathrm{~mm}$ with zero space.

4- Barrow Neurological Institute (BNI) pain intensity scale [7]. This scales describes the level of medication usage. This scale classifies pain into the following grades:

I. No trigeminal neuralgia pain, requires no medication

II. Occasional pain, requires no medication

IIIa. Pain, requires no continued medication

IIIb. Some pain, controlled adequately with medication

IV. Pain improved, but not adequately controlled with medication

V. Continued severe pain without relief.

The trigeminal pain in all patients was assessed by BNI before and after intervention.

\subsection{Gamma Knife Technique for Group I}

The patients in this group were chosen from gamma knife center in Nasser Institute Hospital, with the previous criteria and free of pharmacotherapy at least one week before the start of gamma knife radiotherapy. Gamma knife radiosurgery was performed in all patients using the Leksell gamma unit (model C; Elekta Instruments, Stockholm, Sweden). This version of gamma knife has 201 Co-60 sources and an Automatic Positioning System (APS). A Leksell G stereotactic frame (Elekta Instruments $\mathrm{AB})$ was used. The treatment planning was done using GammaPlan ${ }^{\circledR}$ version 9 developed by Elekta Instruments Inc. It would seem that the desirable dose is between 70 and 90 Gy but there is no clear cut evidence to support either dose in view of variations in other parameters such as shot location, previous treatment and the use of plugs [8]. Patients were followed up by Clinical assessment of pain using BNI pain intensity scale. The scale will be done as follow: Before, Immediately after, One month after, and three months after gamma knife session.

\subsection{Medical Treatment for Group II}

The patients of group II were subjected to The protocol therapy [9] which were used as monotherapy or polytherapy according to the condition:

1) Carbamazepine(CBZ) $300-1000 \mathrm{mg}$ begin with small doses, depending on tolerability, retard version useful at night.

2) Oxcarbazepine $300-1200 \mathrm{mg}$ is better tolerated than carbamazepine, and can be used four times a day.

3) Gabapentin 200-900 mg.

4) Baclofen $50-80 \mathrm{mg}$ begin very slowly, frequent dosage.

5) Lamotrigine $200-400 \mathrm{mg}$ Initially very slow escalation. Can be used in combination with CBZ.

- Pain will be assessed by BNI pain intensity scale. This scale has been applied as follow: Before, One week after, One month after, and three months after medical treatment

We considered pain outcome after three months as: [10] - Good outcome = BNI score I and II and IIIa - Fair outcome $=$ BNI score IIIb - Bad outcome $=$ BNI score IV and $\mathrm{V}$.

\subsection{Statistical Analysis}

The data were tabulated and statistically analyzed using Statistical package of social science (SPSS) Version 14.0.0 software package. Level of significance: the threshold of significance is fixed at 5\% level (P value).P value of $>0.05$ indicates non-significant results. $P$ value of $\leq 0.05$ indicates significant results.P value of $\leq 0.001$ indicates highly significant results. The smaller the $p$ value obtained the more significant are the results.

\section{Results}

Descriptive data of the studied groups showed no statistically significant difference between the two groups regarding age, gender, pain side or distribution of pain (Table 1). Table 2 described Barrow Neurological Institute (BNI) score before, immediately after GKRS and one week after medical treatment, one month and three months after GKRS and medical treatment as there was no statistically significant difference between the two groups regarding pain intensity before GKRS or medical treatment. While group II showed statistical significant improvement one week after pharmacotherapy $(\mathrm{p}=0.01)$. But group I showed statistical significant better outcome than group II after one month of treatment $(\mathrm{p}=0.009)$. Three months after treatment, group I showed highly statistical significant better outcome than group II. This difference was highly statistically significant $(\mathrm{p}=0.001)$. Barrow neurological institute (BNI) score during the study period among group I (Table 3) showed progressive pain improvement among group I as measured by Barrow neurological institute (BNI) scale during the study period and this difference was highly statistically significant $(\mathrm{p}=0.001)$.

Table 4 studied Barrow Neurological Institute (BNI) score during the study period among group II, we found progressive pain improvement among group II as measured by Barrow neurological institute (BNI) scale 
during the study period and this difference was highly statistically significant till one week after medical treatment $(p=0.05)$ and statistically significant at one month without any patient had BNI score I or II through group II study. Table 5 showed overall outcome in both groups and demonstrated that most of patients of group I $(82.4 \%)$ had good outcome while half of the patients of group II $(50 \%)$ had fair outcome.

Table 1. descriptive data of the studied groups

\begin{tabular}{|c|c|c|c|}
\hline & Group I & Group II & P value \\
\hline Age(years) range & $40-59$ & $40-60$ & 0.71 \\
\hline M \pm SD & $49 \pm 6.1$ & $49 \pm 6.95$ & 1.0 \\
\hline Gender(no,\%) male & $19(55.9)$ & $19(55.9)$ & $15(44.1)$ \\
female & $15(44.1)$ & $24(70.6)$ & 1.0 \\
\hline Pain side(no,\%)right & $24(70.6)$ & $10(29.4)$ & \\
left & $10(29.4)$ & & \\
Trigeminal branch & & $4(11.8)$ & \\
distribution(no-\%) & $2(5.9)$ & $7(20.6)$ & \\
V1 & $12(35.3)$ & $2(5.9)$ & \\
V2 & $6(17.6)$ & $16(47.1)$ & \\
V3 & $12(35.3)$ & $3(8.8)$ & \\
V2 + V3 & $1(2.9)$ & $2(5.9)$ & \\
V1 + V2 & $1(2.9)$ & & \\
\hline
\end{tabular}

Table 2. Barrow Neurological Institute ( BNI) score before, immediately after GKRS and one week after medical treatment, one month and three months after GKRS and medical treatment

\begin{tabular}{|c|c|c|c|}
\hline BNI score & Group I (no-\%) & Group II (no-\%) & $P$ value \\
\hline $\begin{array}{c}\text { before therapy: } \\
\text { IV } \\
\text { V }\end{array}$ & $\begin{array}{l}20(58.8) \\
14(41.2)\end{array}$ & $\begin{array}{l}16(47.1) \\
18(52.9)\end{array}$ & 0.33 \\
\hline $\begin{array}{l}\text { immediately after GKRS and one week after medical treatment: } \\
\text { III b } \\
\text { IV } \\
\text { V }\end{array}$ & $\begin{array}{c}1(2.9) \\
23(67.6) \\
10(29.4)\end{array}$ & $\begin{array}{l}10(29.4) \\
18(52.9) \\
6(17.6) \\
\end{array}$ & 0.01 \\
\hline $\begin{array}{l}\text { one month after GKRS and medical treatment: } \\
\text { III a } \\
\text { III b } \\
\text { IV } \\
\text { V }\end{array}$ & $\begin{array}{c}14(41.2) \\
15(44.1) \\
4(11.8) \\
1(2.9)\end{array}$ & $\begin{array}{c}3(8.8) \\
17(50.0) \\
11(32.4) \\
3(8.8)\end{array}$ & 0.009 \\
\hline $\begin{array}{l}\text { three month after GKRS and medical treatment: } \\
\text { I } \\
\text { II } \\
\text { III a } \\
\text { III b } \\
\text { IV } \\
\text { V }\end{array}$ & $\begin{array}{c}11(32.4) \\
7(20.6) \\
10(29.4) \\
3(8.8) \\
3(8.8) \\
0(0.0)\end{array}$ & $\begin{array}{c}0(0.0) \\
0(0.0) \\
8(23.5) \\
15(44.1) \\
8(23.5) \\
3(8.8)\end{array}$ & 0.001 \\
\hline
\end{tabular}

Table 3. Barrow neurological institute (BNI) score during the study period among group I

\begin{tabular}{|c|c|c|c|c|c|}
\hline $\begin{array}{c}\text { BNI } \\
\text { score }\end{array}$ & Before GKRS (no-\%) & immediately after GKRS (no-\%) & one month after GKRS(no-\%) & $\begin{array}{c}\text { three months after GKRS } \\
\text { (no-\%) }\end{array}$ & P Value \\
\hline I & $0(0.0)$ & $0(0.0)$ & $0(0.0)$ & $11(32.4)$ & 0.001 \\
\hline II & $0(0.0)$ & $0(0.0)$ & $0(0.0)$ & $1(20.6)$ & 0.001 \\
\hline IIIa & $0(0.0)$ & $0(0.0)$ & $14(41.2)$ & $3(29.4)$ & 0.001 \\
\hline IIIb & $0(0.0)$ & $1(9.1)$ & $15(44.1)$ & $3(8.8)$ & 0.001 \\
\hline IV & $20(58.8)$ & $23(67.6)$ & $1(11.8)$ & $3(8.8)$ & 0.001 \\
\hline V & $14(41.2)$ & $10(29.4)$ & $1(2.9)$ & $0(0.0)$ & 0.001 \\
\hline
\end{tabular}

Table 4. Barrow Neurological Institute (BNI) score during the study period among group II

\begin{tabular}{|c|c|c|c|c|c|}
\hline $\begin{array}{l}\text { BNI } \\
\text { score }\end{array}$ & $\begin{array}{c}\text { Before medical } \\
\text { treatment(no- } \%)\end{array}$ & $\begin{array}{c}\text { One week medical } \\
\text { treatment(no- } \%)\end{array}$ & $\begin{array}{c}\text { One month medical } \\
\text { treatment }(\text { no- } \%)\end{array}$ & $\begin{array}{c}\text { Three months medical } \\
\text { treatment }(\text { no- } \%)\end{array}$ & $P$ value \\
\hline I & $0(0.0)$ & $0(0.0)$ & $0(0.0)$ & $0(0.0)$ & ----- \\
\hline II & $0(0.0)$ & $0(0.0)$ & $0(0.0)$ & $0(0.0)$ & --- \\
\hline IIIa & $0(0.0)$ & $0(0.0)$ & $3(8.8)$ & $8(23.5)$ & 0.05 \\
\hline IIIb & $0(0.0)$ & $10(29.40$ & $17(50.0)$ & $15(44.1)$ & 0.001 \\
\hline IV & $16(47.1)$ & $18(52.9)$ & $11(32.4)$ & $8(23.5)$ & 0.001 \\
\hline $\mathrm{V}$ & 18(52.9) & $6(17.6)$ & $3(8.8)$ & $3(8.8)$ & 0.001 \\
\hline
\end{tabular}

Table 5. overall outcome in both groups

\begin{tabular}{|c|c|c|}
\hline outcome & groupI(no-\%) & groupII(no-\%) \\
\hline Good & $28(82.4)$ & $9(26.5)$ \\
\hline Fair & $3(8.8)$ & $17(50.0)$ \\
\hline Bad & $3(8.8)$ & $8(23.5)$ \\
\hline
\end{tabular}




\section{Discussion}

We found that ITN was more frequent in right side (70.6\%) than left side (29.4\%) in both groups.

This observation was in agreement with other studies which reported that right side ITN was more frequent: $[11,12,13]$ However in other study, Dellaretti et al. 2008 [14] found the left side ITN was $52.6 \%$ and right side was $47.4 \%$.

We found higher pain distribution in V2 and V3 (41.1\%) among all patients without a significant difference between both groups. This goes in hand with Dusan Urgosik et al. 2005 [15], Chuan-Fu Huang et al. 2008 [12] and Kondziolka et al. 2010 [16] who found higher pain distribution in V2 and V3: $36.5 \%, 64 \%, 56.3 \%$ respectively. Neto et al. 2005 [17] reported that smaller size of foramen rotundum and foramen ovale on the right side in their study accounted for the higher incidence of right V2 and V3 pain distribution. While Bennetto et al. 2007 [18] and Dellaretti et al. 2008 [14] found higher pain distribution in ITN patients was in V2: $35 \%$ and $32.9 \%$ respectively.

The effectiveness of medications in idiopathic trigeminal neuralgia typically wanes over time despite increasing doses, with many patients not able to tolerate side effects, If this fails further developments in neurosurgical and radiosurgical techniques have provided effective treatments with increasingly wider margins of safety [3].

We found only one patient $(2.9 \%)$ showed immediate improvement in pain score (BNI score IIIb) after GKRS, This is in agreement with other studies which reported no marked immediate improvement after GKRS [14,19,20]. While one week after medical treatment, we found ten patients (29.4\%) showed improvement in pain score (BNI score IIIb), with highly statistically significant difference, so the medical treatment showed faster pain relief effect because less time to reach the therapeutic level of the drug. This was in agreement with the finding of Cruccu et al. 2008 [9] who found pain improvement in $58 \%$ of the patients through one week following medical therapy.

One month following GKRS: pain score improvement was noticed: 14 patients $(41.2 \%)$ changed from score IV and $\mathrm{V}$ to score IIIa and 15 patients $(44.1 \%)$ changed from score IV and V to score IIIb. While in medically treated patients: improvement was as follow: 17 patients $(50 \%)$ changed from score $\mathrm{V}$ to score $\mathrm{IIIb}$, and three patients $(8.8 \%)$ changed from score IV to score IIIa. This better response to GKRS was highly statistically significant. This finding is consistent with other studies [13,14,21,22,23].

The latency period was defined by these studies as it is the period between Gamma knife radiosurgery and state of pain improvement. This period is needed by Gamma knife radiosurgery to make DNA necrosis in the nerve and beginning its effect [21]. The effectiveness of medical therapy typically wanes over time despite increasing doses, with many patients not able to tolerate side effects [3].

GKRS treated patients showed pain score improvement: $32.4 \%$ had BNI score I and 20.6\% had BNI score II three months following GKRS while no patients had BNI score I or II in medically treated Group. This difference between both modalities of therapy showed higher statistically significance. This continuous significant improvement of pain among GKRS treated group has been reported by other studies [13,23]. As with the time, Gamma Knife radiation progressively distorts the DNA mapping of the cells of abnormal tissue and make them unable to divid.

Conclusively, our results demonstrated progressive pain improvement among GKRS treated group during the study period as immediately after GKRS $9.1 \%$ of the patients had BNI score IIIb. One month follow up, $44.1 \%$ of the patients had score IIIb and $41.2 \%$ had score IIIa. Three months follow up, $20.6 \%$ had BNI score II and 32\% had score I.

Regarding medically treated group (group II) progressive pain improvement has been demonstrated as one week after treatment $29.4 \%$ ot the patients had BNI score IIIb. At one month follow up, $50 \%$ of the patients had score IIIb and $8.8 \%$ of them had BNI score IIIa.

The overall outcome among group I after three months was $82.4 \%$ of the patients had good outcome, $8.8 \%$ of the patients had fair outcome and $8.8 \%$ of the patients had bad outcome. These results are in agreement with Dellaretti et al. 2008 [14], Little et al. 2008 [24], Hayashi et al. 2009 [21] who found their patients good outcome were $83.1 \%, 83 \%$ and 83 respectively. On the contrary, Sheehan et al. 2005 [25] found that only $44 \%$ of their patients treated by GKRS had good outcome. The differences which had been recorded in results of the previous studies regarding GKRS outcome can be attributed to different treatment techniques as the maximum dose of GKRS, target localization and also to different period of follow up that may reach up to 36 month in some of them [26].

The overall outcome among group II after three months was $26.5 \%$ of the patients had good outcome, $50 \%$ had fair outcome and $23.5 \%$ of them had bad outcome. The results of the present study were in line with those of Cruccu et al. 2008 [9], Oomens and Forouzanfar. 2015 [27]. On the other hand, the results of the present study were not in line with those yielded by Sato et al.2004 [28] who studied the effect of CBZ in 50 patients with ITN and they concluded that 45 patients $(90 \%)$ of them became pain free.

The differences in the results in various studies may be due to different treatment protocols, doses of used drugs and differences in the lengths of the follow-up periods [29].

\section{Conclusion}

- Medical management of ITN (monotherapy or polytherapy) had an intial good results in improving pain intensity as measured by BNI score in comparison with GKRS.

- Through one month, the effect of medical treatment began to wane and the effect of GKRS bagin to appear on ITN patients.

- The effect of GKRS on ITN pain was still evolving through three months follow up while medical treatment typically decreased.

- In those with ITN whom treated by GKRS $82.4 \%$ of patients had overall good outcome

While $26.5 \%$ of pharmacotherapy treated group had overall good outcome. Based on our results and previous studies GKRS is a good choice therapeutic option for use with patients who have ITN. 


\section{References}

[1] Youkilis, AS. And Sagher O (2004): Diagnosis and Nonoperative Management of trigeminal neuralgia. Winn HR Youman's Neurological Surgery; 5 th ed 2987-95.

[2] Zakrzewska JM and MC-Millan R (2011). Trigeminal Neuralgia: The Diagnosis And Management Of Facial Pain Post Grad Med J; 87: 410-16.

[3] Edward AM, Hideyuki K, Ali K and Lunsford LD (2012). Gamma Knife Radiosurgery for Trigeminal Neuralgia .Euro Neurol Rev; 7(3):196-200.

[4] Leksell L (1971). Sterotaxic radiosurgery in trigeminal neuralgia, Acta Chir Scand; 137:311-24.

[5] Elaimy AL, Lamm AF, Demakas JJ, Mackay AR, Lamoreaux WT, Fairbanks RK, Pfeffer RD, Cooke BS, Peressini BJ and Lee CM (2013). Gamma knife radiosurgery for typical trigeminal neuralgia: An institutional review of 108 patients. Surg Neurol Int; 4: 92.

[6] Headache Classification Committee of the International Headache Society (IHS) (2013). The international classification of headache disorders, 3rd ed (beta version). Cephal; 33(9):629-808.

[7] Rogers CL, Shetter AG and Fiedler JA (2000). Gamma knife radiosurgery for trigeminal neuralgia: the initial experience of The Barrow Neurological Institute. Int J Radiat Oncol Biol Phys; 47: 1013-19.

[8] Cheuk AV, Chin LS, Petit JH, Herman JM, Fang HB and Regine WF (2004). Gamma knife surgery for trigeminal neuralgia: outcome, imaging, and brainstem correlates. Int J Radiat Oncol Biol Phys; 60: 537-41.

[9] Cruccu G, Gronseth G, Alksne J, Argoff C, Brainin M and Burchiel K (2008). AAN-EFNS guidelines on trigeminal neuralgia management. Eur J Neurol; 15: 1013-28.

[10] Kondziolka D, Zorro O, Lobato-Polo J, Kano H, Flannery TJ and Flickinger JC (2010). Gamma Knife stereotactic radiosurgery for idiopathic trigeminal neuralgia . J Neurosurg; 112: 758-65.

[11] Maesawa S, Salame C, Flickinger JC, Pirris S, Kondziolka D and Lunsford LD (2001). Clinical outcomes after stereotactic radiosurgery for idiopathic trigeminal neuralgia. J Neurosurg; 94: 14-20.

[12] Chuan-Fu H, Hsien-Tang Tu, Wen-Shan L, Shyh-Ying C and Long-Yau L (2008). Gamma Knife surgery used as primary and repeated treatment for idiopathic trigeminal neuralgia. Neurosurg; 109: 179-84.

[13] Hung-Chuan P, Sheehan J, Chuan -Fu H, Meei-Ling S, Dar-Yu Y and Wen-Ta C (2010). Quality-of-life outcomes after Gamma Knife surgery for trigeminal neuralgia. J Neurosurg; 113:191-98.

[14] Dellaretti M, Reyns N, Touzet G, Sarrazin T, Dubois F, Lartigau E and Blond S (2008). Clinical outcomes after Gamma Knife surgery for idiopathic trigeminal neuralgia: review of 76 consecutive cases. J Neurosurg; 109: 173-78.

[15] Dusan U, Liscak R, Josef N, Vymazal J and Vilibald V (2005). Treatment of essential trigeminal neuralgia with gamma knife Surgery J Neurosurg; 102: 29-33.
[16] Kondziolka D, Zorro O, Lobato-Polo J, Kano H, Flannery TJ and Flickinger JC (2010). Gamma Knife stereotactic radiosurgery for idiopathic trigeminal neuralgia . J Neurosurg; 112: 758-65.

[17] Neto HS, Camilli JA and Marques MJ (2005). Trigeminal neuralgia is caused by maxillary and mandibular nerve entrapment: greater incidence of right-sided facial symptoms is due to the foramen rotundum and foramen ovale being narrower on the right side of the cranium. Med Hypoth; 65: 1179-82.

[18] Bennetto L, Patel Nk and Fuller G (2007). Trigeminal neuralgia and its management. BMJ; 334: 201-05.

[19] Dhople A, Adams JR and Maggio WW (2009). Long-term outcomes of Gamma Knife radiosurgery for classic trigeminal neuralgia: implications of treatment and critical review of the literature. J Neurosurg 111: 351-58.

[20] Aubuchon AC, Chan M, Lovato JF, Balamucki CJ, Ellis TL, Tatter SB, McMullen KP, Munley MT, Deguzman AF, Ekstrand KE, Bourland JD and Shaw EG (2010) Repeat gamma knife radiosurgery for trigeminal neuralgia. Int J Radiat Oncol Biol Phys; 81(4): 1059-65.

[21] Hayashi M (2009). Trigeminal neuralgia. Prog Neurol Surg 22, $182-90$.

[22] Ron I et al, 2010, Ron I, Steven W and Clemens M (2010). Outcomes following single-treatment Gamma Knife surgery for trigeminal neuralgia with a minimum 3-year follow up. J Neurosurg; 112: 766-71.

[23] Park KJ, Kano H, Berkowitz O, and Awan NR. (2011). Computed tomography-guided gamma knife stereotactic radiosurgery for trigeminal neuralgia. Acta Neurochir; 153: 1601-09.

[24] Little AS, Shetter AG, Shetter ME, Bay C and Rogers CL (2008). Long-term pain response and quality of life in patients with typical trigeminal neuralgia treated with gamma knife stereotactic radiosurgery. Neurosurg; 63: 915-23.

[25] Sheehan J, Pan HC, Stroila M and Steiner L. (2005). Gamma knife surgery for trigeminal neuralgia: outcomes and prognostic factors. J Neurosurg; 102: 434-41.

[26] Hafez R and Farouk A (2008). Gamma knife surgery for idiopathic trigeminal neuralgia targeting the neurovascular contact zone: Cairo International Medical Centre initial experience .Pan Arab Journal Of Neurosurg; 12(2):101-105.

[27] Oomens MA and Forouzanfar T (2015). Pharmaceutical Management Of Trigeminal Neuralgia In The Elderly Drugs Aging; 32:717-26.

[28] Sato J, Saitoh T, Notani K, Fukuda H, Kaneyama K and Segami N (2004). Diagnostic significance of carbamazepine and trigger zones in trigeminal neuralgia. Oral Med Endod; 97: 18-22.

[29] Faryabi J and Joolhar M (2014). Treatments' Outcomes of Patients Suffered from Trigeminal Neuralgia in Kerman, Iran J. Dent Shiraz Univ Med Sci., September; 15(3): 140-46. 